\title{
LA INDUSTRIA TRANSGÉNICA: EXPROPIACIÓN DE LA VIDA
}

\author{
Joaquín González Cruz*
}

Universidad Autónoma de Nuevo León, México

Resumen.- La industria transgénica constituye hoy en día un grave problema con muchas aristas, económico, político, social, biológico. Un problema evidentemente de bioética que no debería de estar exento en los análisis criminológicos. La criminología contemporánea debe estar avocada a estudiar los fenómenos pluridimensionales como éste, ya que, o en sus acciones se ven involucradas ciertas formas de delitos o conductas dañinas para la sociedad, o puede constituir un delito por sí mismo.

Palabras clave.- salud vernácula, transgénicos, iatrogenia, convivencialidad, crecimiento industrial

Abstract.- The transgenic industry is today a serious problem with many edges, economic, political, social and biological. Obviously a bioethics problem that should not be free in the criminological analysis. Contemporary criminology should be doomed to study the multidimensional phenomena like this, since their actions or are involved certain types of offenses or conduct harmful to society, or may constitute a crime in itself.

Keywords.- vernacular heath, transgenic, iatrogenic, conviviality, industrial growth

"En la era de la civilización técnica, que ha llegado a ser "omnipotente" de modo negativo, el primer deber del comportamiento humano colectivo es el futuro de los hombres." [Hans Jonas, El principio de responsabilidad ]

\section{INTRODUCCIÓN}

El siguiente trabajo muy bien puede calificarse como el fruto de una reflexión en torno a los límites y alcances de la criminología contemporánea, hasta dónde llegan los problemas concernientes a la criminología y cuáles son las restricciones subjetivas con las que se encuentra. Regularmente cuando se habla de criminología se tiene la primera impresión de que va a tratar con temas relacionados con homicidios, lesiones, robos, con crímenes

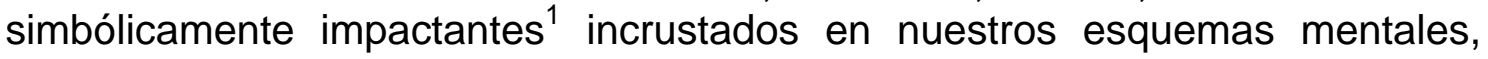

\footnotetext{
* Profesor Ayudante de Cátedra en la Facultad de Derecho y Criminología de la Universidad Autónoma de Nuevo León (México), Investigador colaborador del Centro de Investigaciones Jurídicas de la Facultad de Derecho y Criminología, Licenciado en Criminología por la Universidad Autónoma de Nuevo León (UANL). Máster en curso de Derecho constitucional y gobernabilidad en la Facultad de Derecho y Criminología en la UANL. Correo electrónico: jkohzz@gmail.com

${ }_{1}^{1}$ Los crímenes simbólicamente más impactantes son aquellos considerados "delitos de sangre", que producen un shock inmediato en la subjetividad de las personas, sin embargo, hay otros delitos que por su "naturaleza" tienen consecuencias más profundas y dilatadas, tal es el caso de los delitos políticos o económicos, como los fraudes a gran escala que no se perciben como los delitos de sangre pero que muy bien pueden degenerar el tejido social peor que un homicidio.
} 
como si se hablará de un arquetipo. Sin embargo, las investigaciones criminológicas van más allá de este problema de violencia subjetiva, es decir, también le atañen la violencia sistémica ${ }^{2}$ y lo relacionado con ella, como los delitos de cuello blanco ${ }^{3}$ y la delincuencia organizada que constituye una modalidad de la delincuencia "genérica." Fenómeno muy complejo, ya que resulta difícil detectarla e investigarla por estar interrelacionada con altas concentraciones de poder, gracias a que no hay demarcación clara sobre sus estructuras constitutivas, las cuales se sirven a su vez de las estructuras del Estado y el mercado global, así como por sus peculiaridades parecidas a una empresa cualquiera altamente conectada con las transformaciones económicas a nivel mundial. Empresas aparentemente legítimas y legales, aunque hay que ser honestos en esto, no existe empresa transnacional o multinacional alguna con grandes ganancias que no haya cometido ni un delito para lograr sus fines, de hecho, los fines y medios de una empresa transnacional son muy parecidos a los de una organización delincuencial.

El sociólogo Edwin Sutherland fue el primero en acuñar el concepto de delito de cuello blanco para designar un fenómeno criminal relacionado con personas con un cargo o función pública de status social y políticamente alto o en ejercicio de una profesión, o en palabras del sociólogo estadounidense "El delito de "cuello blanco" puede definirse, aproximadamente, como un delito cometido por una persona de respetabilidad y status social alto en el curso de su ocupación"

Este concepto provocó una ruptura epistemológica en la criminología ya que "... inválida una teoría general que muestre que el delito se debe a la pobreza y a sus patologías relacionadas." ${ }^{5}$ Al abrir este espectro epistemológico se revelan diversos aspectos íntimamente intrincados con el poder político y económico que otrora era pasado por alto categóricamente.

En este sentido se pretende abordar el fenómeno que denominamos como la "industria o empresa transgénica," relacionado con la delincuencia organizada, o más bien, se pretende llegar a un intento de justificación de la "empresa transgénica" como delito de cuello blanco, o como delincuencia organizada. ${ }^{6}$ Esta empresa ha causado diversos daños y perjuicios a la población en general, desde los campesinos, que son los más perjudicados, hacia todas y cada una de las personas consumidoras de estos productos, incluso, hasta llegar a la conclusión de consistir un atentado contra la humanidad. Para ello se iniciará el análisis con unas aproximaciones al problema en las cuales se presenta una panorámica de la cuestión, en donde se enmarcan algunos problemas suscitados a la hora de imponer una visión totalizadora del mundo, como lo pretende la "empresa transgénica." El segundo apartado inicia con la problematización de nuestros constructos principales. Aquí se realizó una pequeña incursión al concepto de salud, primordial para nuestro análisis, con el fin de construirlo críticamente a fines de la investigación. En el apartado

\footnotetext{
2 Para ver un análisis sobre la relación que hay entre la violencia subjetiva y la violencia sistémica: (2009) ZIZEK, S., Seis reflexiones marginales sobre la violencia, Paidós, Barcelona.

${ }^{3}$ (1999) SUTHERLAND, H. E., El delito de cuello blanco (trad. Rosa del Olmo), Ediciones La

Piqueta, Madrid, p. 65.

${ }^{4}$ Ibídem.

${ }^{5}$ Ibídem.

${ }^{6}$ Óp., cit., p. 261.
} 
siguiente damos un breve acercamiento sobre los transgénicos, algunos de sus efectos y sus consecuencias iatrogénicas, este último concepto nos sirvió como punto de anclaje crítico para darle seguimiento a la cuestión. Posteriormente hacemos una revisión esbozada sobre el pensamiento de Ivan Illich a través de algunos de sus conceptos básicos de su teoría, como la convivencialidad y limites al crecimiento, todo ello para acercarnos al problema planteado. Finalmente una crítica a la legislación (mexicana) reguladora de los organismos genéticamente modificados (transgénicos) nos ayuda a encontrar las fallas y contradicciones con las acciones hegemónicas de los políticos y las empresas transnacionales en cuestión, para que de esta forma podamos justificar con razones por qué pensamos que la "empresa transgénica" constituye en sí un delito contra la humanidad, en su forma de delincuencia organizada (o como delito de cuello blanco), y dar algunas propuestas y sugerencias en posteriores investigaciones criminológicas.

\section{APROXIMACIONES A LA CUESTIÓN}

La protección de la salud está estrechamente vinculada con la seguridad, no sólo con la seguridad pública, o por vías selectivamente escogidas que encubren problemas aún más profundos, como el narcotráfico (tema que ha monopolizado la visión pública sobre la salud), sino con la seguridad social, la seguridad o certeza subjetiva (y objetiva) de tener un mejor futuro, la seguridad de establecer y construir el devenir de nosotros mismos y de toda la humanidad. Con esto queremos decir que salud y seguridad no son conceptos dialógicos únicamente concernientes al narcotráfico o temas de "salud pública (o nacional)," los cuales, la mayoría de las veces son "institucionalmente "fabricados." Al contrario, existen un sinnúmero de vicisitudes, algunos considerados delitos otros aun no, que contienen dentro de su (i)-lógica esta dicotomía laberíntica.

Los delitos realizados dentro de la esfera de la salud pueden ser cometidos, como ya sea visto en la incorporación a muchos códigos penales, a través de fármacos, alimentos, contaminación y todo aquello que dañe o perjudique la integridad y la constitución física y/o psicológica de una persona ${ }^{7}$. Muchos de estos delitos que en un primer momento constituyen un atentado contra la salud se convierten en una amenaza contra la seguridad, la libertad, e incluso, contra la vida en sí misma. Un claro ejemplo de esto se encuentra presente en la producción de transgénicos, punto neurálgico de este trabajo.

Como ya se ha enunciado en diversos estudios de distintos campos del saber y en los discursos más cotidianos, la salud es considerada un "bien" que se tiene que cuidar, proteger y salvaguardar. Hay un consenso unánime sobre esta presuposición. Sin embargo, se ha olvidado un debate fundamental llevado a cabo a principios y mediados del siglo pasado que alcanzó un gran impacto en las comunidades científicas pero que nunca llegó a salir en forma de debate y discusión pública. Este debate tenía que ver con la relación entre salud y enfermedad, lo normal y lo patológico, sobre cuáles son los límites de la salud/normalidad y de la enfermedad/patología, cuándo empieza una y termina

\footnotetext{
${ }^{7}$ Ley General de Salud, art. 2. México.
} 
otra, y cómo poder designar a una persona con tal o cual cualidad. ${ }^{8}$ A lo largo de los años este tema ha caído en el olvido y damos por sentado las definiciones proporcionadas por el legislador y por "especialistas" que pretenden tener el monopolio de la verdad. La aparente incontenible fuerza de jerarquización y centralización del saber que ejercen las instituciones públicas y privadas (como las empresas transnacionales) y sus especialistas, amenaza con destruir el horizonte vital de los más vulnerables que no pueden defenderse contra la instauración de interpretaciones sobre el mundo que legitiman una posición en particular de la vida misma. ${ }^{9}$ Este es un problema que abarca las definiciones de salud, vida y libertad. El legislador, el juez, el empresario y el profesionista escolarizado ${ }^{10}$, constantemente fraguan la realidad para todos, sus interpretaciones sobre lo que es legítimo, legal, justo, funcional y verdadero, ejercen una coerción sobre la sustancia misma del mundo y del hombre.

\section{LA SALUD VERNÁCULA}

Aclarando lo anterior y para ahondar en la problematización de nuestros constructos heurísticos, podríamos hacer suposiciones y conclusiones un tanto apresuradas sobre el problema, pero primero sería conveniente plantearnos cuál sería ese problema. El uso-imposición, producción y mercantilización de los transgénicos genera trastornos y perturbaciones no solamente en la salud física y mental de una persona, como ya lo han tratado algunos estudios ${ }^{11}$, sino, y esto es aún más importante, genera, o mejor dicho, degenera las relaciones de los seres humanos con su entorno y con la vida misma. Monopolizar y privatizar la vida, en eso ha consistido lo único que han hecho las grandes empresas transnacionales dedicadas a la producción de transgénicos, no por una falta de "responsabilidad social", sino porque los dos

\footnotetext{
${ }^{8}$ Este debate emergió principalmente en el campo de la medicina, psicología y la sociología, sin embargo, la filosofía (filosofía de la medicina, de la ciencia) aportó muchos elementos relevantes al conocimiento sobre el sentido y significado de éstas categorías "esenciales." Ver. (2006) GARFINKEL, H., Estudios en Etnometodología (trad. Hugo Antonio Pérez Hernáiz), Anthropos, Barcelona; (1968) MEAD, G. H., Espíritu, persona y sociedad. Desde el punto de vista del conductismo social, Paidós, Barcelona; (1986) CANGUIHEM, G., Lo normal y lo patológico ( $7^{\mathrm{a}}$ ed.), Siglo XXI, México; (2001) FOUCUALT, M., Los anormales (Horacio Pons), FCE, México; (1975) FOUCAULT. M. El nacimiento de la clínica, Una arqueología de la mirada médica ( $2^{\mathrm{a}}$ ed.), (trad. Francisca Perujo), Siglo XXI, México; (2002) FOUCAULT, M. Historia de la Locura en la Época Clásica (trad. Juan José Utrilla), Fondo de Cultura Económica, México; (1973) DELEUZE, G. y GUATTARI F., El Anti-Edipo, Barral Editores, Barcelona; (1981) SZASZ, T., La fabricación de la locura. Estudio comparativo de la Inquisición y el movimiento en defensa de la salud mental ( $2^{\mathrm{a}}$ ed.), Editorial Kairós S.A. Barcelona.

${ }^{9}$ Existe una clase privilegiada transnacional que "ejecuta" la formación de intereses y un lenguaje común a expensas y sobre una clase "inferior" (underclass) que parece constituirse a escala mundial. Para ampliar este tema ver: (2005) BALIBAR, E., Violencias, identidades y civilidad. Para una cultura política global (trad. Luciano Padilla y Patricia Wilson), Gedisa, Barcelona, p. 163.

${ }_{10}$ (1975) ILLICH, I., La sociedad desescolarizada (Gerardo Espinosa), Barral editores, Barcelona.

${ }^{11}$ (2000) World Health Organization, Regional Office for Europe European Centre for Environment and Health. Release of Genetically Modified Organisms in the Environment: is it a Health Hazard? WHO/EURO, Rome; (2001) World Health Organization, Regional Office for Europe European Centre for Environment and Health., Safety assessment of foods derived from genetically modified microorganisms, WHO/EURO, Geneva.
} 
"fenómenos," la industria y los transgénicos, comparten la misma lógica interna; son el resultado del mismo proceso histórico, económico, político y social: la subsunción real del capital. ${ }^{12}$ Sin meternos en discusiones dogmáticas sobre este punto espinoso, y sin caer en interpretaciones confusas y complicadas que requerirían un estudio erudito aparte -como el de determinar si la industrialización y el capital(ismo) constituyen en sí mismos un crimen-, podemos vernos tentados a plantearnos la posibilidad de que la producción de transgénicos puede constituir una dificultad tan grave que podríamos llegar a considerarlo como un problema que pone en riesgo la calidad de lo humano.

Llegando a este punto podemos empezar a problematizar nuestros constructos. Tomando como referencia matriz la definición propuesta por la Organización Mundial de la Salud (OMS) que dice lo siguiente: "la salud no es solamente la ausencia de enfermedad, sino el estado de completo bienestar físico, mental y social del individuo,"13 podemos indagar con ello que nos abre un poco la perspectiva y la manera de abordar el concepto de salud. Dejando por ahora la ambivalencia y polivocidad que puede tener la definición proporcionada por la OMS, lo interesante es que este concepto amplía la visión sobre la salud, llevándola fuera del ámbito intrapersonal hacia el social. Es decir, la salud, y con más razón, la salud pública, tienen un componente sustancial: lo social. Entonces, la salud social es el bienestar (salut) de todas las personas que componen la sociedad, no obstante, esto constituye únicamente la apariencia de la estructura social, si lo tomamos al pie de la letra se llegaría a la tesis "corporativista" del funcionalismo sociológico, es decir, que la sociedad consiste en un cuerpo (corpus), un organismo susceptible a enfermarse. ${ }^{14}$ Lo cual no es del todo cierto, como decíamos, es sólo la apariencia fenoménica de un algo más radical, dicho en términos kantianos, que se encuentra "escondido" detrás de una cortina fenomenológica. Con ello pretendemos explicar que la definición obvia el sentido político e histórico de lo que entendemos por salud y bienestar ${ }^{15}$, no todas las naciones ni todas las personas piensan la salud y el bienestar por igual, incluso se llegan a contradicciones fundamentales entre unas y otras.

Es en este sentido en el cual abordábamos este problema más arriba. Las instituciones definen conceptos que se postran por arriba de otros generados por gente que no tiene el poder de reivindicarlos. No obstante, lo importante es que la salud, al tomarla desde lo social, automáticamente tiende a universalizarse, se generaliza, se "humaniza", se vuelve un concepto que podría servir para constituir otros horizontes de posibilidades para el ser humano.

Hasta ahora hemos visto la necesidad de ampliar los límites conceptuales institucionales o especializados. La salud (pública) es algo que concierne

\footnotetext{
${ }^{12}$ (2001) MARX, K., El capital, Siglo XXI, México, p. 73; (2001) NEGRI, A., Marx más allá de Marx (trad. Carlos Prieto del Campo), AKAL, Madrid, pp. 131-136.

${ }^{13}$ (2006) Organización Mundial de la Salud, Constitución de la Organización Mundial de la Salud, OMS, Génova.

${ }_{14}$ (2003) ZAFFARONI, E, R, Criminología. Aproximación desde un margen, Temis, Bogotá.

15 Esta misma circunstancia condiciona y da lugar a una imposición de una imagen sociopolítica de la salud o de la muerte, "se priva a la gente de su visión tradicional de lo que constituye la salud y la muerte" Ver: (1975) ILLICH, I., Némesis médica, Barras Editores, Barcelona, p. 189.
} 
especialmente a los integrantes de una comunidad, no a las Instituciones gubernamentales o a las grandes empresas privadas que todo lo quieren monopolizar. ${ }^{16}$ No pretendo decir que no deban involucrarse en este tema, ya que las personas que conforman una institución son parte de una comunidad, sino que no deben tener pretensiones de acaparar y de imponer una visión del mundo. Para esclarecer esto sería pertinente revisar la etimología del concepto de salud. Salud viene de la voz latina salus, salutis que significa salvación o saludo, la raíz de este verbo salvus, quiere decir intacto o a salvo, y tiene otras connotaciones como entero o total o salvare $y$ salvator que se refiere a salvador (lo cual nos habla de una fuerte influencia cristiana). Entonces, a la salud "pública" (populus, pueblo, población, popular) la podemos entender como: salvaguardar la integridad, la enteres, totalidad o salvación de todos. La salvación total de los seres humanos; lo cual abarca su mundo circundante. Este acercamiento nos adentra a la compresión de salud no desde un plano especializado sino vernáculo del concepto. ${ }^{17}$

De este modo, vemos que las acciones del gobierno dentro del ámbito de la salud pública han olvidado esto y han extendido "su visión de la salud" a poblaciones que no tenían la "necesidad" ${ }^{18}$ de servicios de drenaje, sanidad mental, educación escolarizada, o de métodos de ganadería y agricultura. ${ }^{19}$ Esta subsunción de otras formas de expresión ha creado una nueva pobreza ${ }^{20}$ con respecto a la salud; los pobres, una vez más, son redefinidos no por su incapacidad adquisitiva, sino por su incapacidad de proporcionarse los servicios de la salud pública institucional. Así, podemos ver como la "empresa transgénica" subsume, desde las interpretaciones que se tienen de vida, salud, y libertad, hasta otros medios o formas de producción, pasando por la privatización de la vida y la paz. ${ }^{21}$

\section{PROBLEMAS IATROGÉNICOS DE LOS TRANSGÉNICOS}

Los transgénicos son organismos genéticamente modificados mediante técnicas biológicas sintéticas y recursos de la ingeniería genética, los cuales se elaboran al introducir un gen de un organismo en el ADN de otro, sea este de la misma especie o de otro completamente diferente, para conferir a la planta un rasgo especifico nuevo, como la resistencia a herbicidas. ${ }^{22}$ Esta tecnología y

\footnotetext{
${ }^{16}$ Este punto se tocará más adelante en éste ensayo

${ }^{17}$ (1990) ILLICH, I., El género vernáculo, Editorial Joaquín Mortiz, México.

18 (1996) ILLICH, I., "Necesidades" en: W. SACHS (editor), Diccionario del desarrollo. Una guía del conocimiento como poder, PRATEC, Perú, (primera edición en inglés en 1992), p. 157-176. ${ }^{19}$ (2000) LÓPEZ, S., "La salud en el contexto de la nueva salud pública", Salud pública de México, Instituto Nacional de Salud Pública, México, vol. 42, no. 4, julio-agosto, pp. 370-372.

20 (1974) ILLICH., Convivencialidad (Matea P. de Gossmans), Barral editores, Barcelona, p 104.

${ }^{21}$ Muchos científicos que hacen apología de los "beneficios" de los transgénicos justifican su desarrollo y producción mediante discursos "progresistas" a favor de la cura de los males del mundo, el hambre mundial, la escases alimenticia aparejada con la económica y todo lo que esto conlleva, sin darse cuenta que el verdadero "mal" es la pésima distribución de las riquezas, es decir, como está estructurado el aparato económico global.

${ }^{22}$ (2001) TORRICO, B., "¿Qué son y cómo se construyen los Organismos Genéticamente Modificados? Dos visiones de la ciencia: El Dogma Central y el Genoma Fluido" en Los Transgénicos en el Contexto de Bolivia, La Paz-Bolivia, Memoria del Seminario 12 y 13 de diciembre, pp. 37-43.
} 
sus resultados (como las semillas por ejemplo) están sujetos a regulaciones y normas de propiedad intelectual, lo cual quiere decir que los organismos genéticamente modificados están sometidos a un registro o patente que establece su uso y el aprovechamiento exclusivo. A esto se le puede llamar, sin el peligro se sonar extremista: patentar la vida. No solamente de la vida en el sentido estrictamente biológico, sino también, dadas las circunstancias que se conminan en la fabricación de estos productos, como el uso monopólico de las semillas transgénicas, su infertilidad originada por los procesos de modificación genéticos que ocasionan que las semillas no vuelvan a germinan después de haberse utilizado, la obligación de pagar mucho más por estas semillas, (ya que se paga por el proceso que es costoso), y las represalias que se toman al utilizarlas sin el consentimiento de los dueños aunque no se tenga conocimiento de que se esté cultivando con estas semillas (por error 0 descuido), entre otros factores, a privatizar la vida en el sentido económico, social y cultural. Esto consiste la privatización la vida, a ello nos referíamos con imponer una interpretación de la visión del mundo que abarca el lenguaje técnico y otras formas de expresión humanas.

Los productos transgénicos además de generar una dependencia económica producen una dependencia creativa, limitan los espacios de autonomía y convivencialidad. $^{23}$ No se limitan únicamente a restringir la capacidad de producción de innumerables trabajadores de la tierra (en el caso concreto de las semillas modificadas genéticamente) sino constriñen las cualidades que los hacen seres humanos, es decir, la única manera en como ellos se reconocen a través su trabajo se está viendo acechada por la exclusividad que las empresas transgénicas imponen a las personas interdependientes del campo. Entonces, los transgénicos, además de constituir un problema de equilibrio medio ambiental, balance ecológico, biodiversidad ${ }^{24}$ y de salud fisiológica, constituyen un serio problema económico, político y social, que como ya vimos, también se engloba o tiene relación con vicisitudes implicadas en el uso intensivo y extensivo del concepto de salud ${ }^{25}$.

Asimismo, el uso extensivo de los alimentos y demás productos transgénicos han creado lo que Ivan Illich denominó como efectos iatrogénicos, ${ }^{26}$ lo cual

${ }^{23}$ (1974) ILLICH., Convivencialidad (Matea P. de Gossmans), Barral editores, Barcelona.

24 TORRICO, B., "¿Qué son y cómo se construyen los Organismos Genéticamente Modificados? Dos visiones de la ciencia: El Dogma Central y el Genoma Fluido" en Los Transgénicos en el Contexto de Bolivia...Óp. cit., p. 37.

${ }^{25}$ Sobre esto ya se han descubierto algunos fenómenos como la huida de genes o el flujo genético que atentan contra el equilibrio medioambiental, la intrusión de nuevos elementos ajenos a la biodiversidad puede conllevar consecuencias inabarcables y de alto riesgo para toda la humanidad. "Estudios han mostrado que los cultivos de organismos genéticamente modificados pueden contaminar las plantas no transgénicas. Los impactos varían de acuerdo al lugar, de modo que en áreas con altos niveles de endemismo es posible que experimenten alto niveles de erosión e incluso la extinción de especies. Asimismo, se conjetura sobre la pérdida de biodiversidad dada las abruptas transformaciones que implica la alteración del medio en que se encuentran los organismos, trayendo en su conformación variados tipos de genes ajenos." Vid. (2008) OLESKI, M., "Transgénicos: Perspectivas y riesgos desde América del Sur", Revista Mad., No. 19, Universidad de Chile, Septiembre, pp. 89-98.

${ }^{26}$ La iatrogenia, aunque en un principio se formula como concepto médico, el pensador vienés Ivan Illich realizó una "traspolación" de ese ámbito hacia el de todo sistema social, político, científico o económico que se guíe bajo la lógica industrial del crecimiento desmedido ilimitado. Lo cual pone muy en claro en sus obras de investigación radical sobre el aparato médico, 
quiere decir que el uso de los transgénicos y las políticas sobre ello, han creado en sí "enfermedades" estructurales legadas a futuras generaciones. Si llevamos está lógica consecuentemente podemos afirmar que los transgénicos son en sí una "enfermedad" generadora de enfermedades, a nivel físico, biológico, ambiental, pero también a nivel social, político y económico, ya que sus efectos no sólo se reflejan en el presente inmediato, en el acontecimiento sustantivo, también se proyectarán al futuro, sobre el devenir, donde las generaciones venideras encontrarán sus consecuencias ulteriores y radicales, así como una cantidad inconmensurable de problemáticas y vicisitudes causadas por el uso indiscriminado y negligente de los transgénicos, pero también de la lógica expansiva y voraz de la industrialización y del tardocapitalismo $^{27}$ en la cual la "empresa transgénica" conforma un caso ejemplar de esta racionalidad. ${ }^{28}$

A todo ello se le añade la irracional y acelerada "patentización" de estos productos que muchas personas aún no han percatado, o denunciado. Ésta conducta aparentemente legal y legítima va más allá de una mera protección a la producción intelectual, técnica o industrial, se están jugando la libertad y la sustancia misma de lo vivo: los genes y la biomasa lo cual constituye un intento perverso y cruel por generar ganancias y riquezas a expensas de la vida y del hombre. Asimismo, son usados conceptos hiperespecializados, ambiguos y equívocos manipulados a voluntad, únicamente inteligibles por aquellos portadores de un saber jerarquizado y excluyente ${ }^{29}$.

Como hemos visto, los efectos negativos de los transgénicos (si es que tienen algún otro), abarcan no únicamente problemas de salud interpretada desde lo biomedioambiental, sino también desde lo sociopolítico-económico y cultural como ya habíamos señalado, donde el lenguaje y nuestra praxis, que constituyen nuestra forma de comprender, "codificar" y transformar la realidad, se ven acuciantemente amenazados por ésta empresa fútil y frívola. Por ello es de importante relevancia limitar el crecimiento de esta industria, o dicho en palabras de Illich, ponerle límites al crecimiento industrial, ${ }^{30}$ no solamente de un crecimiento económico (como se habitúa a pensarse) sino de uno político y cultural (lingüístico), aparejados y consustancializados uno al otro, es decir, se deben de limitar las intenciones y acciones que a niveles políticos y culturales

energético y de transporte. (1975) ILLICH, I., Némesis médica (trad. Carlos Godard Buen Abad), Barral editores, Barcelona; (1985) Convivencialidad, Joaquín Mortiz, México; (1978) Energía y Equidad. Desempleo creador (trad. Verónica Petrowitsch), Posada, México.

${ }^{27}$ El capitalismo tardío o el tardocapitalismo como lo han hecho llamar algunos pensadores del renombre de Habermas o Giddens, se guía bajo los esquemas de máximo crecimiento, cero límites, subsunción total del capital, entre otros. Esto último ha dado lugar a otros estudios y formas de expresión más acertadas sobre el estado actual del sistema socioeconómico global. Pensadores como Félix Guattari contribuyeron a estos análisis de gran alcance y de importante relevancia; él denominó este fenómeno como Capital Mundial Integrado (CMI) y autores como Antonio Negri y Michael Hardt como Imperio. Ver: (1996) GUATTARI, F., Las tres ecologías, Pre-textos, Valencia., y (2002) HARDT. M., NEGRI. A., Imperio (1 ${ }^{a}$ ed.) (trad. Alcira Bixio), Paidós, México.

${ }^{28}$ El filosofo alemán Marcuse hace una increíble exposición sobre la racionalidad de la lógica capitalista que en muchos sentidos todavía se puede considerar vigente, Ver: (1972) MARCUSE, H., El hombre unidimensional (trad. Antonio Elorza), Seix Barral, Barcelona.

${ }^{29}$ (1978) FOUCAULT, M: Microfísica del poder (trad. Julia Varela y Fernando Álvarez-Uría), La Piqueta, Madrid.

${ }^{30}$ (1974) ILLICH, I., Energía y equidad, Barral editores, Barcelona. 
tienden a imponer una manera de actuar y de ver el mundo. ${ }^{31}$ Tal y como nos dice Illich:

"La exploración y el reconocimiento políticos de las condiciones necesarias para la equidad y la eficacia tendrán que fijar los límites al modo industrial de producción." 32

\section{CONVIVENCIALIDAD Y LÍMITES AL CRECIMIENTO INDUSTRIAL}

La convivencialidad según Ivan Illich quiere decir una forma o un arte de vivir en armonía y equilibro con el medio circundante del hombre y con sus capacidades creativas, así como del aumento del rango de autonomía para ejercerla. La convivencialidad forja la apertura de nuevos y mejores horizontes para las generaciones venideras, ya que supone acciones, procesos, mecanismos y técnicas sustentables.

Podemos hacer una actualización y comparación a la afirmación de Ivan Illich sobre la iatrogenia y némesis médica, a saber, que la "empresa transgénica" ha llegado a convertirse en una grave amenaza a la salud. ${ }^{33} \mathrm{La}$ dependencia que se tiene a estos productos y a la superespecialización de profesionales que atienden lo relacionado a este ámbito de la tecnociencia, influye en todas las relaciones sociales vitales de la humanidad, tanto en países "ricos" como en países "pobres", donde en estos últimos, los estragos se están sintiendo cada vez más abrumadores y falaces. Éste carácter político del proceso tecnocientífico ${ }^{34}$ lo denominamos, siguiendo los mismos planteamientos del pensador vienés y recordando lo anterior, como la "patentización de la vida."

Esta empresa basada en especialistas y "profesionales" de la genética ha sobrepasado los límites tolerables que resultan "patógenos" para la vida, ya que producen daños económicos, sociales, políticos, biológicos y medioambientales superiores a sus posibles beneficios; además de que tienden a encubrir los intereses y las condiciones políticas que suponen un daño a la salud de la sociedad. Así mismo, expropian el poder de las personas (de campesinos y trabajadores de ese sector primario) para producir sus propios recursos, realizar su labor con sus medios y moldear su ambiente. Este monopolio sobre la metodología y la tecnología agricultora es un ejemplo característico del uso indebido del poder político y económico que se realiza a través del susodicho "progreso científico" en provecho de la industria y no de los seres humanos. ${ }^{35}$

\footnotetext{
${ }^{31}$ Para las "empresas transgénicas," y en general, todas las empresas industriales, el mundo es interpretado en base a ganancias, riquezas, acumulación, pérdidas, consumo, intercambio mercantil, cantidad sobre calidad, expansión (visto como desarrollo o progreso), etc. El monopolio institucional de la "visión" del mundo es llevado a cabo por la institución mercantil y monetaria, tal como lo expresa Nils Christie en su obra: (2004) CHRISTIE, N., Una sensata cantidad de delito (trad. Cecilia Espeleta y Juan Iosa), Editores del Puerto, Buenos Aires, p. 2349.

${ }^{32}$ ILLICH, I., Némesis médica...Óp. cit., p. 199.

${ }^{33}$ (1975) ILLICH, I., Némesis médica, Barras Editores, Barcelona, p. 9.

34 (1986) HABERMAS, J., Ciencia y técnica como ideología (trad. Manuel Jiménez Redondo), Tecnos, Madrid.

${ }^{35}$ ILLICH, I., Némesis médica, Óp. cit., p. 9. Asimismo el criminólogo Nils Christie ha estudiado el fenómeno de la "expansión del pensamiento industrial" sobre los centros penitenciarios y otros sistemas sociales con ayuda de las herramientas conceptuales de Ivan Illich. Ver. (1993)
} 
La ineficiencia de esta empresa es un hecho de facto que se da por sentado en este trabajo ya que, además de ser muy costosa, constituye un alto riesgo para toda la humanidad y su devenir. Los "síntomas sociales" causados por esta actividad rapaz y beligerante consisten en el descontento social, una posible movilización de las fuerzas y emociones de una población desesperada que se siente acosada y orillada a cometer actos violentos, la criminalización de estas personas, ${ }^{36}$ su marginación económica, entre muchos otros.

El monopolio fútil de estas empresas sobre los productos necesarios para realizar un proceso, los medios y modos de producción, sobre los genes y la vida, hacen que estas actividades encarnadas en la historia ancestral de muchas generaciones (agricultura) se transformen en problemas técnicos ${ }^{37}$ susceptibles de ser centralizados, especializados y jerarquizados. La convivencialidad se ve gravemente deteriorada por todas estas vicisitudes, las personas involucradas (campesinos, agricultores y demás trabajadores de la tierra) se ven altamente afectadas por ello, sus relaciones con su mundo tal y como ellos lo conocen, se ve minado por la presencia instigadora de estas empresas colosales que controlan su vida a niveles infinitesimales. Cambian por completo el modo en como ellas se relacionan con su medio ambiente y su adaptación a éste. Las herramientas de convivencialidad para lograr enfrentarse autónomamente a su mundo se ven gravemente constreñidas y limitadas.

De esta manera podemos ver como la salud entendida en el sentido vernáculo, como ya lo vimos en apartados anteriores, los límites a la empresa transgénica y la convivencialidad tienen un correlato mutuo, la convivencialidad necesita de una visión como el de la salud vernácula para que esta pueda tener un efecto total y positivo en los seres humanos, así como, no hay salud vernácula sin las herramientas necesarias de la convivencialidad, todo ello aunado a imponer límites desmedidos a toda clase de crecimiento industrial que genera problemas iatrogénicos desgarradores del tejido social.

\section{UN ACERCAMIENTO CRÍTICO A LA LEY DE BIOSEGURIDAD DE ORGANISMOS GENÉTICAMENTE MODIFICADOS EN MÉXICO: ¿QUIÉNES SON LAS VICTIMAS?}

En este apartado se realiza un breve análisis crítico sobre el discurso institucional encargado de proteger y regular los procesos vivenciales

CHRISTIE, N., La industria del control del delito. ¿La nueva forma del Holocausto? (trad. Sara Costa), Editores del Puerto, Buenos Aires., y (2004) Una sensata cantidad de delito (trad. Cecilia Espeleta y Juan Iosa), Editores del Puerto, Buenos Aires.

${ }^{36}$ Existen algunos casos de campesinos que han sido demandados y encarcelados por empresas como Monsanto por haber utilizado sin darse cuenta o no, sus productos "legalmente patentados" sin autorización. Ver el caso paradigmático de: U.S. Court of Appeals for the federal Circuit, Monsanto Company and Delta and Pine Land Company v. David D. Thomason and Lucknow, Inc et al., Field January 22, 2002. La familia Thomasen, de Louisiana, Estados Unidos, fue demandada por más de un millón de dólares por Monsanto después de que, sin saberlo, sembraron algodón transgénico de esa empresa. La familia compró semillas sin marca y no sabían que estaban usando semillas patentadas de Monsanto, perdieron la demanda y tuvieron que declararse en bancarrota.

${ }^{37}$ (1975) ILLICH, I., Némesis médica (trad. Carlos Godard Buen Abad), Barral editores, Barcelona. 
complejos como los relacionados a los transgénicos. La ley de bioseguridad de organismos genéticamente modificados vigente en México pretende tener el propósito:

"regular las actividades de utilización confinada, liberación experimental, liberación en programa piloto, liberación comercial, comercialización, importación y exportación de organismos genéticamente modificados, con el fin de prevenir, evitar o reducir los posibles riesgos que estas actividades pudieran ocasionar a la salud humana o al medio ambiente y a la diversidad biológica o a la sanidad animal, vegetal y acuícola."38

Todo esto es muy ambiguo ${ }^{39}$ y más que una ley que proteja la biodiversidad y sanidad parece ser una ley reguladora del comercio y uso de los transgénicos, que como ya vimos, constituyen en sí mismo un riesgo a la salud en todo el sentido adjudicado anteriormente.

Como todas las leyes (fragmentos más o menos ligados de enunciados discursivos) no son coherentes al momento de cotejarse con la realidad y las prácticas. Muchas de las veces se hace caso omiso a las políticas de protección y vigilancia presupuestas en su contenido. Como por ejemplo, en este caso: "Establecer procedimientos administrativos y criterios para la evaluación y el monitoreo de los posibles riesgos que puedan ocasionar las actividades con organismos genéticamente modificados en la salud humana o en el medio ambiente y la diversidad biológica o en la sanidad animal, vegetal o acuícola." ${ }^{40} \mathrm{Si}$ fuera de esta manera se hubieran prohibido todos los procesos por los cuales el maíz Bt. (maíz genéticamente modificado) se introdujo en el sector primario, secundario y terciario. Producto natural que representa no sólo una gran parte de la economía agrícola de México, sino un distintivo cultural que otorga identidad y sentido de pertenencia a muchos grupos y personas del país, especialmente a aquellos íntimamente relacionados con el trabajo en el campo, ya que el tejido vital de su existencia se encuentra condicionado por una especie de simbiosis cultural con la tierra y todo lo que está relacionado con ello. Asimismo en el propio artículo, fracción XI, se incumplen sus presupuestos constituyentes, ni se determinan las bases para el establecimiento "caso por caso" de áreas geográficas libres de organismos genéticamente modificados en las que se prohíba su uso, y aquellas en las que se restrinja la realización de actividades con determinados organismos genéticamente modificados, y ni se mantiene un régimen de protección especial de cultivos de los cuales México sea centro de origen, especialmente del maíz.

En cuanto a los principios en materia de bioseguridad de la presente ley se nos menciona que el "Estado tiene la obligación de garantizar el derecho de toda persona a vivir en un medio ambiente adecuado para su alimentación, salud,

\footnotetext{
${ }^{38}$ Ley de bioseguridad de organismos genéticamente modificados, art. 1., México.

${ }^{39}$ La utilización de frases, terminología y conceptos sospechosos abundan en este tipo de leyes que encubren interese económicos y políticos, no hay una definición clara sobre qué es un nivel adecuado y eficiente de protección y habrá que preguntarse para quién es adecuado y eficiente, lo que se entienda por estos conceptos definirá los límites de acción, lo que es perjudicial y dañino a la salud, por su falta univocidad pueden ser manipulados según los intereses en cuestión. Ley de bioseguridad de organismos genéticamente modificados, art. 2., frac I., México.

${ }^{40}$ Ley de bioseguridad de organismos genéticamente modificados, art. 2., frac VI., México.
} 
desarrollo y bienestar." ${ }^{41}$ El Estado como garante de la protección de la población, si es que se pretende vivir en un Estado de derecho democrático, tiene que realizar dichas acciones anteriormente citadas, si se es congruente con ello, entonces, la empresa transgénica en sí misma constituye un atentado en contra de dichos presupuestos democráticos, ya que altera y pervierte el medio ambiente de las personas, en los sentidos en que se desarrollo en los capítulos de este trabajo. Asimismo, daña exponencialmente los alimentos, el "desarrollo social" (a reservas de lo que esto signifique), el bienestar de las personas y consecuentemente su salud. Entonces, la ley, en lugar de proteger los intereses populares (del pueblo), justifica y enmascara los estragos generados por las acciones de la empresa transgénica.

Otro punto clave dentro del análisis de esta ley se centra en el sospechoso y declarado apoyo el desarrollo tecnológico y la investigación científica sobre los organismos genéticamente modificados que puedan contribuir a satisfacer las necesidades de la Nación. No hay una aclaración sobre cuáles son éstas necesidades que la Nación tanto necesita y si las personas dañadas en su patrimonio cultural y existencial son parte de dicha Nación; al parecer no lo son, los campesinos, agricultores y demás trabajadores de ese sector están a un peldaño de convertirse en parias, en marginados, en el "radicalmente otro."42 Entonces, ¿cuáles son las necesidades de la Nación? ¿El bienestar de todas las personas pertenecientes a ella, o sólo el de algunas concentradas en las altas esferas del poder político y económico global? ¿La Nación atiende a los campesinos o las grandes transnacionales dueñas del futuro de los más vulnerables? Nos parece que la respuesta es muy clara, es de todos el conocimiento de que a los campesinos y agricultores de este país (México) se les coaccionan constantemente sus derechos y vínculos políticos y jurídicos. ${ }^{43}$ No por nada son los primeros en las filas de los revolucionarios, de los guerrilleros, de aquellas multitudes fastuosas llenas de rencor y esperanzas. Se les hace más "pobres," se les engaña y miente constantemente, se les dice que les proporcionarán información sobre los efectos socioeconómicos de los organismos genéticamente modificados, cuando en realidad se les obliga a usarlos cualesquiera que sean las consecuencias para ellos y su futuro. No únicamente a ellos se les esconde y modifica la información por conveniencia de los interesados, sino a todo mundo, hay un silencio intransmutable entorno a estas cuestiones que se han callado todos los medios de comunicación masiva

\footnotetext{
${ }^{41}$ Ley de bioseguridad de organismos genéticamente modificados, art. 9., frac II., México. Asimismo, podemos ver las contradicciones de esta ley cuando nos dice que "la bioseguridad de los OGMs tiene como objetivo garantizar un nivel adecuado de protección en la esfera de la utilización confinada, la liberación experimental, la liberación en programa piloto, la liberación comercial, la comercialización, la importación y la exportación de dichos organismos resultantes de la biotecnología moderna que puedan tener efectos adversos para la conservación y utilización sustentable del medio ambiente y de la diversidad biológica, así como de la salud humana y de la sanidad animal, vegetal y acuícola." Estas contradicciones se perciben mediante un cotejo con los hechos y los estudios científicos. Los organismos, por calidad de ser infértiles, no tienen un uso sustentable hacia el medio ambiente, contaminan este mismo con el llamado flujo genético o huida o de genes que corrompen y contagian otros organismos con su carga genética modificada y por tanto, representan un atentado contra la salud en general.

42 (1999) BAUMAN, Z., Trabajo, consumismo y nuevos pobres (trad. Victoria de los Ángeles Boschiroli), Gedisa, Barcelona, pp. 109-120.

${ }^{43}$ (2005) VIRGOLINI, J., La razón ausente ensayo sobre Criminología y critica política, Editores del Puerto, Buenos Aires, p. 236.
} 
más "importantes" y grandes del país. ${ }^{44}$ Con esto, se está violando derechos fundamentales no sólo en esta ley ${ }^{45}$ sino en la Ley federal de transparencia y acceso a la información pública gubernamental, entre muchas otras.

Si se analizara aun más en profundidad estas disposiciones legales se llegaría a la conclusión de que son un enredo terminológico lleno de lagunas, y manchas llenas de subjetividad irreflexiva dudosa y equivoca, ya que si uno de los propósitos es velar por que estos organismos o empresas no causen daños graves o irreversibles, se tendría que desechar por completo todas las pretensiones egoístas de la empresa transgénica, y si fuera de este modo, entonces, estaríamos criminalizando a la personas incorrectas. Por consiguiente, no son los campesinos "abusivos" que "roban" o no dicen sobre la pertenencia de estos "transproductos," que además se "enriquecen" con sus precarias cosechas, quienes son los delincuentes, criminales y canallas, son los empresarios de las grandes multinacionales como Monsanto, Bayer y DuPont y los políticos cómplices de sus acciones, los verdaderos delincuentes, son ellos, los científicos y técnicos acríticos vendidos y comprados por sus laboratorios los verdaderos criminales, es la empresa transgénica en su totalidad, la real, culpable y malhechora de que miles de personas pierdan sus trabajos y cosechas, que se hallen esclavizados a su merced, los criminalicen y pierdan todos sus horizontes vitales constitutivos.

\section{A MODO DE CONCLUSIÓN}

Con todo lo anterior ahora podemos resolver el problema planteado al principio de este trabajo, ¿la empresa transgénica constituye en sí un delito de cuello blanco? ¿Es ésta la máscara de una de tantas organizaciones delincuenciales? La respuesta ya parece haberse contestado así misma a lo largo del trabajo, en definitiva pensamos y constatamos que ésta industria es un delito en sí mismo, no es solamente que las grandes multinacionales como Monsanto y DuPont comentan delitos de cuello blanco al evadir impuestos justificándose con actitudes seudohumanistas, como erradicar el hambre del mundo, defraudando a campesinos obligándoles a pagar una suma costosa de dinero por sus productos, o engañar al público escondiendo y enmascarando la información relacionada con los daños de sus servicios y productos, sino que las actividades que conforman su núcleo constitutivo de la empresa transgénica constituyen un grave y peligros atentado contra la salud, libertad y por tanto, la vida de todas las personas afectadas por ella.

Son ya muchos los que desconfían de la empresa transgénica y solo necesitan de más datos para corroborar esos temores, sin embargo la información esta parcelada y no es muy clara debido a un terrible ocultamiento de la información. No obstante, se puede llegar a conclusiones en base a los efectos

44 (2009) Entrevista con el Dr. Jorge Enrique Linares Salgado, "Bioética y alimentos transgénicos" en Revista Digital Universitaria, UNAM, México, vol. 10, no. 4, 10 de Abril, pp. 39.

45 "El Estado Mexicano garantizará el acceso público a la información en materia de bioseguridad y biotecnología a que se refiere esta Ley, de conformidad con lo establecido en este ordenamiento y en las disposiciones aplicables a la materia de acceso a la información pública gubernamental" Ley de bioseguridad de organismos genéticamente modificados, art. 9., frac XVIII., México. 
de ésta empresa, la criminalización de los trabajadores de la tierra, la acumulación de capital beligerante, la destrucción de organismos naturales (es decir, no modificados genéticamente) debido a la huida de genes y el fluido genético, la contaminación ambiental producida por los químicos utilizados, los daños a la salud física insidiosos, los desequilibrios medioambientales, económicos y sociales que ha producido, todo ello debe de ser denunciado y constituido como delito. Se deben implementar restricciones a este tipo de ejercicio tecnocientífico que muchos consideran inaplazables y obligatorias pero que son consideradas tan radicales (para los beneficiarios de estas empresas) que resulta inaceptable para la mayoría de los políticos.

Asimismo, como ya hemos visto, consideramos igual de inaplazable el hecho de ponerle un límite razonable al crecimiento de esta lógica industrial que subsume todo a su paso, desde la imposición de una determinada visión del mundo con sus conceptos y terminología hiperespecializada, a la irracional "patentización de la vida" por los técnicos, científicos, empresarios y políticos que únicamente buscan la manera de generar beneficios económicos a expensas de la libertad, la salud y la vida de todos los que compartimos este mundo. Proponemos que los límites a estas acciones empresariales deberían de ir encaminadas en un principio a prohibirles que se entrometan en el sector primario dejando a los trabajadores que realicen sus labores según las condiciones tecnológicas, científicas y tradicionales particulares, que no se les obligue a adquirir las semillas y demás productos de las empresas transgénicas y que no constituyan una competencia infranqueable y voraz para ellos.

Lo siguiente sería poner límites a las patentes, no todo se puede y debe patentar, hay cosas que no le pertenecen a nadie, o de las que todos somos dueños, la vida es una de ellas, privatizar la vida por medio de los genes y la biomasa podría convertirse en un antecedente al estilo fascista, especialmente en una sociedad altamente burocratizada y tecnificada: si se es dueño de la vida se es dueño de la muerte ${ }^{46}$. El puro intento de patentar tal cosa debería de ser considerado como un atentado a la vida, a la humanidad. Patentar significa privatizar y la privatización conlleva a la arbitrariedad y ésta, como su última consecuencia desastrosa, al holocausto. ${ }^{47}$ La diferencia entre patentar la vida por medios jurídico-técnicos intelectuales a sentirse dueño de la vida de los demás (como el caso de los nazis, quienes decidían quien moría o hasta cuando se tenía que mantener con vida o no en la segunda guerra mundial) es corta, con lo cual no quiero decir que "patentar" la vida sea una condición suficiente de un (neo) fascismo, pero si su condición necesaria.

Por tanto, el primer paso para la abolición de la empresa transgénica, si es que se nos permite pensar un tanto utópicamente ${ }^{48}$, sería la denuncia de sus efectos y consecuencias, y posteriormente, la catalogación de ésta actividad como delito, como crimen de lesa humanidad. Vemos en esto algo con demasiadas dificultades que no se discuten en el trabajo, como todo el entramado político-económico que hay a nivel global y obstaculizan este fin, ya que existen una cantidad enorme de intereses involucrados en este tipo de

46 (2005) FOUCUALT, M., Historia de la sexualidad. La voluntad de saber (trad. Ulises Guiñazú), Siglo XXI, México, p. 167-169.

${ }^{47}$ (1997) BAUMAN, Z., Modernidad y holocausto (trad. Ana Mendoza), Sequitur, Madrid.

${ }^{48}$ Aunque acaso todo el pensamiento sea utópico, ya que no tiene lugar, el pensamiento no tiene un topoi determinado, fijo o estable, observable empíricamente. 
"negocios." Sin embargo, pensamos que un primer acercamiento a estos casos a nivel criminológico serviría para darle un nuevo enfoque tanto a la criminología a nivel teórico, como a las políticas de seguridad o de programas de prevención a nivel práctico. Si la criminología empieza a indagar y adentrarse a nuevos campos como el de la bioética, encontrará una nueva manera de abordar las problemáticas sociales, políticas y jurídicas que le conciernen. ${ }^{49}$ Todo esto para llevar a cabo el fin propuesto de ésta ciencia, que en definitiva no es la prevención del delito, la prevención constituye únicamente un medio, sino: más justicia social.

\section{BIBLIOGRAFÍA}

(2009) Entrevista con el Dr. Jorge Enrique Linares Salgado, "Bioética y alimentos transgénicos" en Revista Digital Universitaria, UNAM, México, vol. 10, no. 4, 10 de Abril.

(2005) BALIBAR, E., Violencias, identidades y civilidad. Para una cultura política global (trad. Luciano Padilla y Patricia Wilson), Gedisa, Barcelona.

(1999) BAUMAN, Z., Trabajo, consumismo y nuevos pobres (trad. Victoria de los Ángeles Boschiroli), Gedisa, Barcelona.

(1997) BAUMAN, Z., Modernidad y Holocausto (trad. Ana Mendoza), Sequitur, Madrid.

(1986) CANGUIHEM, G., Lo normal y lo patológico (7ª ed.), Siglo XXI, México.

(1993) CHRISTIE, N., La industria del control del delito. ¿La nueva forma del Holocausto? (trad. Sara Costa), Editores del Puerto, Buenos Aires,.

(2004) CHRISTIE, N., Una sensata cantidad de delito (trad. Cecilia Espeleta y Juan losa), Editores del Puerto, Buenos Aires.

(1973) DELEUZE, G. y GUATTARI F., El Anti-Edipo, Barral Editores, Barcelona.

(2001) FOUCUALT, M., Los anormales (Horacio Pons), FCE, México.

(1975) FOUCAULT. M. El nacimiento de la clínica, Una arqueología de la mirada médica ( $2^{\mathrm{a}}$ ed.), (trad. Francisca Perujo), Siglo XXI, México.

(1996) GUATTARI, F., Las tres ecologías, Pre-textos, Valencia.

(1986) HABERMAS, J., Ciencia y técnica como ideología (trad. Manuel Jiménez Redondo), Tecnos, Madrid.

(2002) HARDT. M., NEGRI. A., Imperio ( $1^{\text {a }}$ ed.) (trad. Alcira Bixio), Paidós, México.

(1985) ILLICH, I., Convivencialidad, Joaquín Mortiz, México.

(1975) ILLICH, I., Némesis médica, Barras Editores, Barcelona.

(1974) ILLICH, I., Energía y equidad, Barral editores, Barcelona.

(1990) ILLICH, I., El género vernáculo, Editorial Joaquín Mortiz, México.

49 . El holocausto aporta más a la sociología (criminología) en la forma de abordar un problema, es decir, metodológicamente, que la sociología al holocausto. Vid. (1997) BAUMAN, Z., Modernidad y holocausto (trad. Ana Mendoza), Sequitur, Madrid. 
(1996) ILLICH, I., "Necesidades" en: W. SACHS (editor), Diccionario del desarrollo. Una guía del conocimiento como poder, PRATEC, Perú (primera edición en inglés en 1992), p. 157-176.

(2000) LÓPEZ, S., "La salud en el contexto de la nueva salud pública", Salud pública de México, Instituto Nacional de Salud Pública, México, vol. 42, no. 4, julio-agosto.

(1972) MARCUSE, H., El hombre unidimensional (trad. Antonio Elorza), Seix Barral, Barcelona.

(2001) MARX, K., El capital, Siglo XXI, México.

(2001) NEGRI, A., Marx más allá de Marx (trad. Carlos Prieto del Campo), AKAL, Madrid.

(2008) OLESKI, M., "Transgénicos: Perspectivas y riesgos desde América del Sur", Revista Mad., No. 19, Universidad de Chile, Septiembre, pp. 89-98.

(1999) SUTHERLAND, H. E., El delito de cuello blanco (trad. Rosa del Olmo), Ediciones La Piqueta, Madrid.

(1981) SZASZ, T., La fabricación de la locura. Estudio comparativo de la Inquisición y el movimiento en defensa de la salud mental ( $2^{\mathrm{a}}$ ed.), Editorial Kairós S.A. Barcelona.

(2001) TORRICO, B., “¿Qué son y cómo se construyen los Organismos Genéticamente Modificados? Dos visiones de la ciencia: El Dogma Central y el Genoma Fluido" en Los Transgénicos en el Contexto de Bolivia, La Paz-Bolivia, Memoria del Seminario 12 y 13 de diciembre, pp. 37-43.

(2005) VIRGOLINI, J., La razón ausente ensayo sobre Criminología y critica política, Editores del Puerto, Buenos Aires.

(2003) ZAFFARONI, E, R, Criminología. Aproximación desde un margen, Temis, Bogotá.

(2009) ZIZEK, S., Seis reflexiones marginales sobre la violencia, Paidós, Barcelona.

(2000) World Health Organization, Regional Office for Europe European Centre for Environment and Health. Release of Genetically Modified Organisms in the Environment: is it a Health Hazard? WHO/EURO, Rome.

(2001) World Health Organization, Regional Office for Europe European Centre for Environment and Health, Safety assessment of foods derived from genetically modified microorganisms, WHO/EURO, Geneva.

(2006) Organización Mundial de la Salud, Constitución de la Organización Mundial de la Salud, OMS, Génova.

Ley de bioseguridad de organismos genéticamente modificados, México.

Ley General de Salud, México.

(2002) U.S. Court of Appeals for the federal Circuit, Monsanto Company and Delta and Pine Land Company v. David D. Thomason and Lucknow, Inc et al., Field January 22. 